\title{
Minocycline pigmentation of the cardiac valves and aorta in a 29-year survivor of liver transplant
}

\author{
Maria A. Cohen, BA, ${ }^{a}$ Scott R. Owens, $\mathrm{MD},{ }^{\mathrm{b}}$ and Bo Yang, $\mathrm{MD}, \mathrm{PhD}^{\mathrm{c}}$ \\ From the ${ }^{\mathrm{a} N o r t h e a s t}$ Ohio Medical University, Rootstown, Ohio; ${ }^{\mathrm{b}}$ Department of Pathology and ${ }^{\mathrm{c}}$ Cardiovascular \\ Center, University of Michigan, Ann Arbor, Mich. \\ Disclosures: Authors have nothing to disclose with regard to commercial support. \\ Received for publication March 6, 2016; accepted for publication March 12, 2016; available ahead of print April \\ $20,2016$. \\ Address for reprints: Bo Yang, MD, PhD, Cardiovascular Center, University of Michigan, 1500 E Medical Center \\ Dr, Ann Arbor, MI 48109-5853 (E-mail: boya@umich.edu). \\ J Thorac Cardiovasc Surg 2016;152:1618-9 \\ $0022-5223 / \$ 36.00$ \\ Copyright (c) 2016 by The American Association for Thoracic Surgery \\ http://dx.doi.org/10.1016/j.jtcvs.2016.03.046
}

A 34-year-old man who received a liver transplant 29 years ago was incidentally found to have a $6.5-\mathrm{cm}$ asymptomatic aortic root aneurysm with mild aortic insufficiency. Given the aneurysm size, a valve-sparing aortic root replacement was recommended. The patient's medical history included congestive heart failure, chronic renal failure, biliary atresia, Crohn's disease, and chronic minocycline use for acne.

Operative findings were extensive discoloration of the aortic valve cusps, aorto-mitral curtain into the mitral valve (Figure 1), and media of the ascending aorta. The aortic valve was enlarged and stretched with mild calcification of aortic valve annulus. The right coronary sinus wall was thinned out and ventricularized. Because of the quality of the valve and dysfunction of other organs, an aortic root replacement was performed with a 29-mm Freestyle porcine aortic valve (Medtronic Inc, Minneapolis, Minn) with the ascending aorta with a 26-mm Dacron graft.

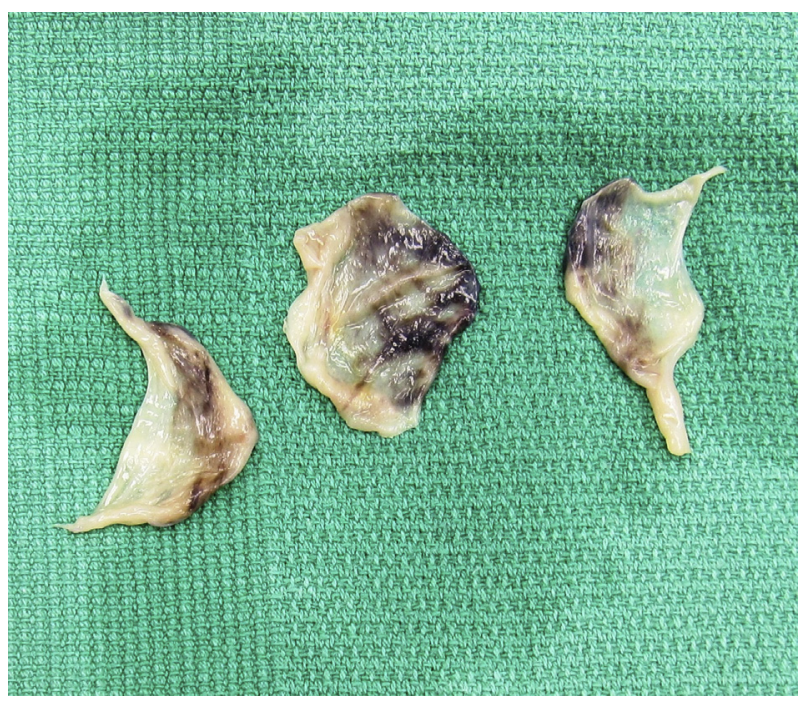

FIGURE 1. Intraoperative macroscopic view shows black discoloration of the aortic valve cusps on a sterile towel.

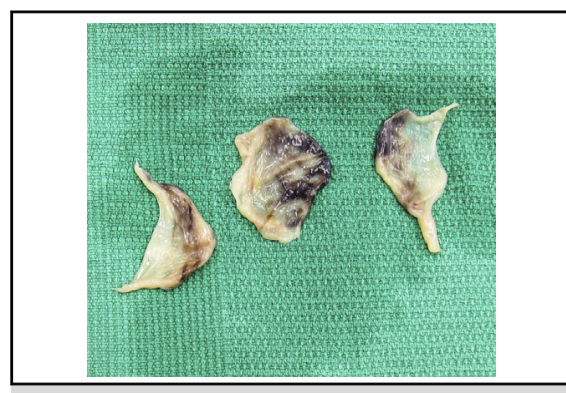

Intraoperative macroscopic view found black discoloration of the aortic valve cusps.

\section{Central Message}

A 34-year-old man who received a liver transplant 29 years ago, with a history of minocycline use, had a finding of black pigmentation of cardiac tissue during aortic root aneurysm.

See Editorial Commentaries page 1619 and 1621 .

The patient had an unremarkable postoperative course and was discharged 6 days later. Pathology revealed patches of hemorrhage and myxoid degeneration of the aortic valve leaflet with subtle pigmentation on Fontana-Masson stain. The aorta and aortic root had no significant abnormality except for atherosclerosis with no dissection (Figure 2, $A-C)$. The liver report found chronic rejection and no fibrosis with Trichrome stain.

Black cardiac tissue pigmentation has been reported rarely. ${ }^{1-4}$ Two causes are minocycline use or alkaptonuria. No case reports were found of black cardiac tissue pigmentation in liver transplant recipients, although minocycline may cause liver failure. ${ }^{5}$ Black pigmentation caused by minocycline seemingly does not affect cardiac valve functionality. ${ }^{2,3}$ A valve-sparing aortic root replacement was not chosen because of the patient's chronic liver dysfunction, high-risk coagulopathy after a long cardiopulmonary bypass, and uncertainty of survival and "black" aortic valve durability. The bioprosthesis selection was large enough for future once to twice valve-in-valve transcatheter aortic valve replacement. Mechanical valve and Coumadin use were not recommended because of frequent liver biopsy.

\section{References}

1. Belcher E, Soni M, Azeem F, Sheppard MN, Petrou M. Minocycline-induced pigmentation of the aortic valve and sinuses of Valsalva. Ann Thorac Surg. 2009;88:1704. 

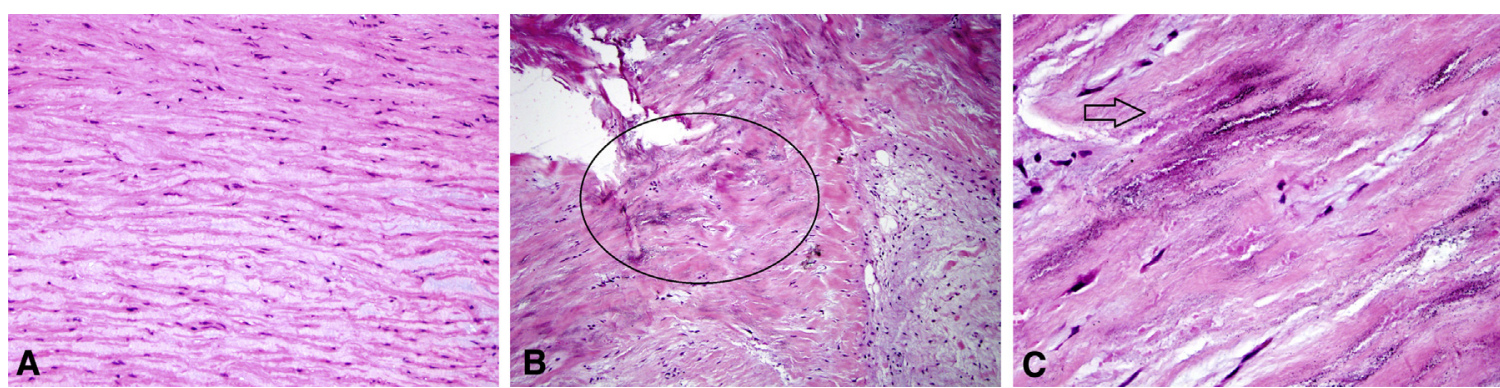

FIGURE 2. A, Fibers of tunica media of the ascending aorta mixed with areas of myxoid degeneration, no pigment (hematoxylin-eosin, 200 $\times$ ). B, Different area of the aortic valve with clouds of pigment (circled) (hematoxylin-eosin, 100×). C, High-magnification view of pigmented area on the aortic valve (arrow) (hematoxylin-eosin, $400 \times$ ).

2. Tsunekawa T, Jones KW, Doty JR. Black pigmented aortic valve and sinus of Valsalva caused by life-long minocycline therapy. Interact Cardiovasc Thorac Surg. 2014;19:339-40

3. Butler JM, Marks R, Sutherland R. Cutaneous and cardiac valvular pigmentation with minocycline. Clin Exp Dermatol. 1985;10:432-7.
4. Hiroyoshi J, Saito A, Panthee N, Imai Y, Kawashima D, Motomura N, et al. Aortic valve replacement for aortic stenosis caused by alkaptonuria. Ann Thorac Surg. 2013;95:1076-9.

5. Pohle T, Menzel J, Domschke W. Minocycline and fulminant hepatic failure necessitating liver transplantation. Am J Gastroenterol. 2000;95:560-1.

\title{
EDITORIAL COMMENTARY
}

\section{Blue-black pigmentation of heart valves. Is it as evil as it looks?}

\author{
Tomohiro Tsunekawa, MD, PhD, ${ }^{a}$ and Kent W. Jones, $\mathrm{MD}^{\mathrm{b}}$
}

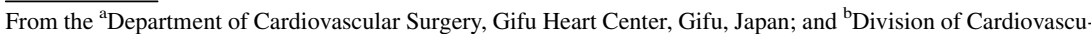
lar and Thoracic Surgery, Intermountain Medical Center, Murray, Utah.

Disclosures: Authors have nothing to disclose with regard to commercial support.

Received for publication July 18, 2016; accepted for publication July 25, 2016; available ahead of print Aug 21, 2016.

Address for reprints: Tomohiro Tsunekawa, MD, PhD, Department of Cardiovascular Surgery, Gifu Heart Center, 4-14-4, Yabuta-minami, Gifu, Gifu, Japan (E-mail: ttsune0707@ hotmail.co.jp).

J Thorac Cardiovasc Surg 2016;152:1619-20

$0022-5223 / \$ 36.00$

Copyright (C) 2016 by The American Association for Thoracic Surgery

http://dx.doi.org/10.1016/j.jtcvs.2016.07.049
}

Minocycline is a semisynthetic tetracycline used for the treatment of a wide range of various infections. Although minocycline has proven to be a very safe, and more recently comes under the spotlight because of its cardioprotective potential, ${ }^{1}$ various drug-specific side effects have been reported (ie, tissue pigmentation, systemic lupus erythematosus-like syndrome, autoimmune hepatitis, and polyarteritis nodosa). ${ }^{2}$ Pigment deposition in human tissue can occur in association with long-term minocycline therapy. Most of the pigmentations involve the skin, thyroid gland, sclera, nails, and bones. Pigmentation rarely is reported in heart valves.

So far, there are 3 clinical reports, including our experience, and 1 cadaveric report that describe minocyclineinduced heart valve pigmentation. ${ }^{4-7}$ In this issue of the Journal, Cohen and colleagues ${ }^{8}$ added another experience.

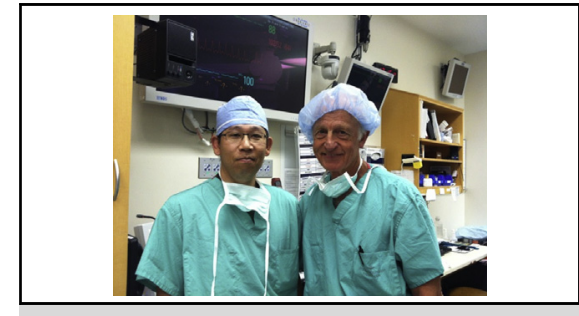

Tomohiro Tsunekawa, MD, PhD, and Kent W. Jones, $\mathrm{MD}$

\section{Central Message}

Pigmentation in human tissue can occur after long-term minocycline therapy. Pigmentation is reported rarely in heart valves. Long-term durability of the pigmented heart tissues is still unclear.

See Article page 1618. 